\title{
Isolation of Anaerobic Bacteria from the Peritoneal Fluid of Patient who has Unstrangulated Umbilical Hernia
}

\author{
Dogan $\mathbf{M}^{1}$, Kucukkartallar $\mathbf{T}^{2}$, Feyzioglu B $^{1}$, Ozdemir $\mathbf{M}^{1 *}$, Baykan $\mathbf{M}^{1}$ and Baysal $\mathbf{B}^{1}$
}

${ }^{1}$ Department of Microbiology, Necmettin Erbakan University Meram Medical School, Turkey

${ }^{2}$ Department of General Surgery, Necmettin Erbakan University Meram Medical School, Turkey

\begin{abstract}
Aim: In cases of ventral hernia, in the presence of complications such as strangulation, a variety of intestinal bacteria can penetrate to peritoneal fluid and can cause peritonitis. However, these infections are rare in unstrangulated hernia cases. In this case report, it is emphasized that anaerobic bacteria and other bacteria can be isolated from patients with unstrangulated umbilical hernia to be cause of peritonitis.

Case report: The 94-year-old female patient with unstrangulated ventral hernia was operated on as an emergency. The liquid that has accumulated in the hernia sac was taken for Gram stain and culture. Five ml peritoneal fluid was inoculated in the BACTEC plus Anaerobic F (Becton Dickinson-Maryland, USA) bottle. In addition, the fluid sample was inoculated on blood agar and EMB (eosin methylene blue) agar medium for aerobic isolation, and was inoculated on Schaedler agar medium (Oxoid, Hampshire, United Kingdom) for anaerobic isolation, and they was incubated at $37^{\circ} \mathrm{C}$. Isolated facultative anaerobic bacteria were identified by using conventional methods; anaerobic bacterium was identified by using conventional methods, the API 20 a panels and An-Ident Discs tests.

In the microbiological examination by Gram stain, no microorganism was observed. E. coli and Enterococcus spp. were identified as facultative anaerobic bacteria, and $B$. fragilis as anaerobic bacterium. After surgery of the patient, ceftriaxone and metronidazole were ordered. According to the culture results, ciprofloxacin was replaced by ceftriaxone in the treatment and the patient was discharged by healing.

Conclusion: In patients with unstrangulated ventral hernia, anaerobic bacteria and other bacteria may be cause of peritonitis due to penetration of intestinal flora to peritoneal fluid.
\end{abstract}

Keywords: Umbilical hernia; Unstrangulation; Anaerobe; Bacterium

\section{Introduction}

Anaerobic bacteria can be isolated from the human body as a component of the normal flora. These bacteria are mostly saprophytic microorganisms and may be cause infection in a variety of situations as having the predisposing factor for anaerobic infection [1-3]. These infections are usually mixed, and isolated microorganisms vary according to the localization. Anaerobic infections in humans generally originate from endogenous flora, and Bacteroides species have been mostly isolated in the clinical specimens. This was followed by Peptostreptococcus, Fusobacterium and Gram positive non-spore forming bacteria [1-3].

In the conditions that have impaired function or tissue integrity as strangulated ventral hernia in patients, peritoneal fluid can be infected with translocation of variety of intestinal microorganisms and this condition can be cause peritonitis. However, these infections are rare in uncomplicated cases such as unstrangulated hernia [1-3]. In this case report, it is emphasized that anaerobic bacteria and other bacteria can be isolated from patients with unstrangulated umbilical hernia to be cause of peritonitis.

\section{Case Report}

A 94-year-old female patient was admitted to the emergency department of Meram Medical Faculty with complaining of abdominal pain. In the abdominal examination, unstrangulated umbilical hernia was observed and there was mild tenderness in the abdomen. The patient was undergone underwent surgery, and hernia was repaired under the local anesthesia because of the patient old. The liquid that has accumulated in the hernia sac was taken for Gram stain and culture.
After surgery of the patient, ceftriaxone and metronidazole were ordered empirically.

Five $\mathrm{ml}$ from peritoneal fluid that has accumulated within the hernia sac was inoculated BACTEC plus Anaerobic F (Becton Dickinson-Maryland, USA) flask, and it was incubated at $37^{\circ} \mathrm{C}$. In addition, the fluid sample was inoculated on blood agar and EMB (eosin methylene blue) agar medium for aerobic isolation and was inoculated on Schaedler agar medium (Oxoid, Hampshire, United Kingdom) for anaerobic isolation, and they were incubated at $37^{\circ} \mathrm{C}$.

In the microbiological examination by Gram stain no microorganisms was observed. No microorganisms were observed in aerobic and anaerobic agar media, but the blood culture appliance (BACTEC) given positive signal. Then, the subculture were performed to Schaedler agar medium (Oxoid, Hampshire, United Kingdom) for anaerobic isolation, and were performed to blood agar and EMB agar for aerobic isolation.

Isolated facultative anaerobic bacteria were identified as $E$. coli

*Corresponding author: Ozdemir M, Department of Microbiology, Necmettin Erbakan University Meram Medical School, Turkey, E-mail: mehmetozdem@yahoo.com

Received March 07, 2013; Accepted June 20, 2013; Published June 28, 2013

Citation: Dogan M, Kucukkartallar T, Feyzioglu B, Ozdemir M, Baykan M, et al. (2013) Isolation of Anaerobic Bacteria from the Peritoneal Fluid of Patient who has Unstrangulated Umbilical Hernia. J Med Microb Diagn 2: 124. doi:10.4172/21610703.1000124

Copyright: (C) 2013 Dogan M, et al. This is an open-access article distributed under the terms of the Creative Commons Attribution License, which permits unrestricted use, distribution, and reproduction in any medium, provided the original author and source are credited. 
Citation: Dogan M, Kucukkartallar T, Feyzioglu B, Ozdemir M, Baykan M, et al. (2013) Isolation of Anaerobic Bacteria from the Peritoneal Fluid of Patient who has Unstrangulated Umbilical Hernia. J Med Microb Diagn 2: 124. doi:10.4172/2161-0703.1000124

Page 2 of 2

and Enterococcus spp. by using conventional methods and antibiotic susceptibility testing was performed by disk diffusion method. Isolated anaerobic bacterium was identified as $B$. fragilis, by using conventional methods and the API 20 a panel, and An-Ident Discs tests and Antimicrobial susceptibility testing was performed by E test methods.

In the antibiotic susceptibility tests, the E. coli and B. fragilis were susceptible to the antibiotics that were ordered empirically. The therapy was continued with ciprofloxacin and metronidazole during two weeks because Enterococcus spp. was isolated. The patient was discharged by healing without any complication.

\section{Discussion}

Although ventral hernias may be asymptomatic, patients may be admitted to the clinician because of abdominal pain. This pain may occur sometimes because of complications such as strangulation and incarceration $[4,5]$. In the presence of ventral hernias that have complications as strangulation and incarceration, peritoneal fluid may be infected with intestinal flora bacteria and it may be cause of peritonitis. These microorganisms that may lead to contaminate the abdomen are often anaerobic bacteria, gram-negative bacilli and enterococci. As much as $60 \%$, the anaerobic bacteria can be isolated in these infections. However, if there isn't any predisposing factor as strangulated hernia, these infections rarely observed $[3,6,7]$.

De Ruiter et al. [6] have reported that isolated microorganism from $69 \%$ of cases with sepsis in abdominal fluid samples, and $70 \%$ of the isolated microorganism were mixed microorganisms that including anaerobic bacteria. Anaerobic and facultative anaerobic bacteria were commonly isolated in the peritoneal fluid samples by Stone et al. [7]. Al-Saadi et al. [8] have reported that the most frequently isolated bacteria were E. coli and Bacteroides in the peritoneal fluid sample of the patients who were operated on appendectomy that most of them appendix were perforated or incarcerated. Anaerobic bacteria were isolated from peritoneal fluid samples by Dogan and Baysal and in this study; the most common isolated anaerobic bacterium has been reported as B. fragilis [9].

A variety of reasons, microorganisms can be isolated as cause of infection in the peritoneal fluid. However, this case was remarkable with some characteristics. As a priority, cooperation with the patient because of old age was difficult. In abdominal examination, there was no marked sign. Any complication as strangulation was unexpected with the examination. Although microorganisms were not detected in the microbiological examination of peritoneal fluid, microorganisms which can be normally found in intestinal flora were isolated by using of the anaerobic culture bottle that used for the blood culture at the routine and has an automated incubation system. One of isolated microorganisms were an anaerobic bacterium that can be overlooked most of the time because of the difficulties have been experienced to the isolation and identification of these bacteria. Explain transition these bacteria into the peritoneal fluid were not detected to any other pathology.

As a result, even if there is no complication as strangulation to patients with abdominal ventral hernia, it should be considered that anaerobic and other bacteria may be cause of peritonitis.

\section{References}

1. Kiyan M (1999) Anaerop bakteriler (Anaerobic bacteria). Temel ve Klinik Mikrobiyoloji (Basic and Clinical Microbiology). Ankara: Günes Kitabevi 611-22.

2. Gürler N (2005) Anaerop enfeksiyonlar ve laboratuvar tanisi (Anaerobic infections and laboratory diagnosis). Anaerop Bakteri Infeksiyonlari (Anaerobic Bacterial Infections). Ankara: Bilimsel Tip 9-34

3. Winn WC, Koneman EW, Allen SD, Procop GW, Janda WM, Schreckenberge PC et al. (2006) the Anaerobic Bacteria. Konemans Color Atlas and Textbook of Diagnostic Microbiology. Philadelphia: Lippincott Williams \& Wilkins.

4. Nieuwenhuizen J, Kleinrensink GJ, Hop WC, Jeekel J, Lange JF (2008) Indications for incisional hernia repair: an international questionnaire among hernia surgeons. Hernia 12: 223-225.

5. Mathur S, Bartlett AS, Gilkison W, Krishna G (2006) Quality of life assessment in patients with inguinal hernia. ANZ J Surg 76: 491-493.

6. De Ruiter J, Weel J, Manusama E, Kingma WP, vander Voort PH (2009) Theepidemiology of intra-abdominal flora in critically All patients with secondary and tertiary abdominal sepsis. Infection 37: 522-527.

7. Stone HH, Kolb LD, Geheber CE (1975) Incidence and significance of intraperitoneal anaerobic bacteria. Ann Surg 181: 705-715.

8. Al-Saadi AS, Al-Wadan AH, Hamarnah SA, Amin H (2007) Is abandoning routine peritoneal cultures during appendectomy justified? Saudi Med J 28 : 1827-1829.

9. DoÄŸan M, Baysal B (2010) Identification of anaerobic bacteria isolated from various clinical specimens and determination of antibiotic susceptibilities. Mikrobiyol Bul 44: 211-219. 